Kong. Res. J. 2(2) : 146-150, 2015

ISSN 2349-2694

Kongunadu Arts and Science College, Coimbatore.

\title{
EFFECT OF INDOLE -3- ACETIC ACID ON CALLUS INDUCTION FROM LEAF EXPLANT OF OCIMUM BASILICUM LINN.
}

\author{
Shillpa Sree, V.N., V. Sirangeevi, S. Deeksha, G. Bhuvaneswari, G. Ramya, M. Gogul Ramnath, R. \\ Krishnaveni, S. Vasantharani and R. Thirugnanasampandan* \\ PG and Research Department of Biotechnology, Kongunadu College of Arts and Science College, Coimbatore. \\ *E.mail: rtsampandan@yahoo.com
}

\begin{abstract}
Ocimum basilicum L. belongs to the family Lamiaceae; contains plenty of phytochemicals with significant nutritional as well as health benefits. Antioxidant activity of methanol extract of Ocimum basilicum callus was evaluated using various antioxidant assays. Proliferated callus was obtained on half-strength MS media supplemented with $1.40 \mu \mathrm{M}$ IAA. The callus extract showed considerable DPPH radical scavenging, hydroxyl radical scavenging and ferrous ion chelation activity with $\mathrm{IC}_{50}$ value of $16.05,170.7$ and $29.16 \mu \mathrm{g} / \mathrm{mL}$ respectively.
\end{abstract}

Keywords: Ocimum basilicum, Lamiaceace, in vitro callus production, free radical scavenging activity.

\section{INTRODUCTION}

Ocimum basilicum L. commonly called as Sweet Basil belongs to the family Lamiaceace is a native plant of Indo Malayan region. It is called the "king of herbs" which contains plenty of phytochemicals with significant nutritional as well as health benefits (Jayasinghe et al., 2003). Sweet basil is cultivated for production of essential oils, dry leaves as a culinary herb, condiment/spice or as an ornamental plant (Zheljazkov et al., 2007). Sweet Basil has shown unique health protecting effects due to its important flavonoids and volatile oils. The unique array of active constituents called flavonoids found in basil provides protection at cellular level. Orientin and vicenin are two water soluble flavonoids that have been of particular interest in basil (Nyak and Uma, 2005). Aromatic leaves and flowering parts of $O$. basilicumare traditionally used as stimulant and tonic in folk remedies to treat various ailments such as poor digestion, stomach ache, feverish illnesses, nausea, abdominal cramps, gastro enteritis, migraine, insomnia, depression, gonorrhoea, dysentery and chronic diarrhoea exhaustion (Chopra et al., 1986). Externally, they have been applied for the treatment of acne, insect stings, snake bites and skin infections (Martin and Ernst, 2004).

\section{MATERIALS AND METHODS}

\subsection{Tissue culture studies}

\subsubsection{Explants selection and mode of sterilization}

Leaf explants were collected from actively growing plants and washed thoroughly in running tap water followed by Teepol treatment for 5-10 min.The explants were subsequently surface sterilized with $0.1 \%(\mathrm{w} / \mathrm{v})$ mercuric chloride solution for 2-3 min and washed 3-4 times with sterile double distilled water for duration of $15 \mathrm{~min}$ with an interval of $5 \mathrm{~min}$ for each wash.

\subsubsection{Method of media preparation}

MS (Murashige and Skoog) medium (half strength) was employed in the present study. For the preparation of medium only analytical reagents of "Hi-media" grade chemicals and Borosil glassware's were used. Double distilled water was used for preparing the media. The nutrient media basically consists of inorganic salts, carbon source, vitamins and amino acids. Stock solutions were prepared separately for macronutrients, micronutrients, iron, potassium iodide and vitamins. All the chemicals were weighed accurately in electronic weighing machine (And Electronic balance, ER-182 A). All the stock solutions were poured in to well stoppered sterilized bottles and preserved in a refrigerator at $4^{\circ} \mathrm{C}$. Specific quantity of the stock solutions and growth regulators were pipetted onto a little beaker. The final volume was made up to one litrewith distilled water. 
To the above said media, $3 \%$ sucrose was added and $\mathrm{pH}$ was adjusted to 5.8 with either $0.1 \mathrm{~N}$ $\mathrm{NaOH}$ or $0.1 \mathrm{~N} \mathrm{HCl} \mathrm{using} \mathrm{a} \mathrm{pH}$ meter (ELICO), further $0.8 \%$ agar (extra pure gelling point $32-35^{\circ} \mathrm{C}$, Hi media, Bombay) was added, melted in a water bath and the medium was dispensed into $25 \mathrm{~mL}$ ( $25 \times 150$ $\mathrm{mm}$ ) test tubes (10-15 mL medium). The tubes after covering with cotton plug were autoclaved at $1.06 \mathrm{~kg}$ pressure/sq $\mathrm{cm}$ for about $20 \mathrm{~min}$ at $121^{\circ} \mathrm{C}$. The autoclaved medium in the culture tubes were cooled and allowed to solidify as slants and were stored at $2^{\circ} \mathrm{C}$ in the dark for future use. The inoculation was done after five days to ensure that the tubes were free from contamination.

\subsubsection{Growth regulator and its preparation}

Growth regulatornamely indole 3-acetic acid was used in the experiments. The growth regulator was stored at $4^{\circ} \mathrm{C}$ until use.

\section{a) Auxins and their preparation}

Auxin namelyindole 3 -acetic acid (IAA) was used in this experiments. The stock solution was prepared by dissolving $10 \mathrm{mg}$ of IAA in $1 \mathrm{~mL}$ of ethanol.Then the volume was made up to $100 \mathrm{~mL}$ with sterile double distilled water and different concentrations $(0.28-2.8 \mu \mathrm{M})$ were used.

\subsubsection{Culture conditions}

The cultures were maintained at $25 \pm 2^{\circ} \mathrm{C}$ under a $16 \mathrm{hr}$ photoperiod of 50-60 $\mu \mathrm{mol} \mathrm{m}^{-2} \mathrm{~S}^{-1}$ flux intensity provided by cool white fluorescent tubes. Each treatment consisted of five replicates and experiment was repeated thrice.

\subsubsection{Callus induction}

Leaf explants were used for callus induction on MS (half strength)medium supplemented with various concentrations of IAA $(0.28-2.8$

$\mu \mathrm{M})$ individually. Percentage of callus induction was recorded after 15 days of culture.

\subsubsection{RAPD analysis}

DNA isolation was performed with modified protocol of Padmalatha and Prasad (2006). Freshly collected leaf and callus sample (both in vivo and in vitrorespectively) was ground in CTAB extraction solution using a mortar and pestle along with $0.1 \%$ of PVP. The pulverized leaves were quickly transferred to centrifuge tubes. The tubes were incubated at $65^{\circ} \mathrm{C}$ in hot air oven or water bath for 60-90 min with intermittent shaking and swirling for every 30 min. Equal volume of chloroform: isoamylalcohol (24:1) was added and mixed properly by inversion for $30 \mathrm{~min}$ and centrifuged at $12,000 \mathrm{rpm}$ for $15 \mathrm{~min}$ at room temperature. The supernatant was carefully decanted and transferred to a new tube. $1 / 10^{\text {th }}$ volume of $\mathrm{CTAB} / \mathrm{NaCl}$ solution was added and mixed by inversion. Chloroform: isoamylalcohol extraction step was repeated. Aqueous phase was transferred to fresh tubes and equal volume of CTAB precipitation solution was added and centrifuged at $3000 \mathrm{rpm}$ for $5 \mathrm{~min}$ at $4^{\circ} \mathrm{C}$. Supernatant was removed and the pellet was washed with high salt TE buffer. $0.6 \mathrm{~mL}$ of isopropanol was added and centrifuged at 10,000 $\mathrm{rpm}$ for $15 \mathrm{~min}$ at $4^{\circ} \mathrm{C}$. Supernatant was removed and the pellet was washed with $70 \%$ ethanol, centrifuged at $10,000 \mathrm{rpm}$ for $2 \mathrm{~min}$ at $4^{\circ} \mathrm{C}$. Supernatant was removed and air dried the pellet. The pellet was resuspended in TE buffer.

\subsubsection{Preparation of Agarose gel}

Agarose gel (1.5\%) was prepared by adding $0.75 \mathrm{~g}$ of agarose (low EEO grade, HiMedia, India) in $50 \mathrm{~mL}$ of $1 \mathrm{X}$ TAE buffer. It was heated to dissolve agarose. Ethidium bromide $(0.5 \mathrm{mg} / \mathrm{mL})$ was added, mixed well and poured into the gel casting platform with well former. The gel was allowed to polymerize at room temperature.

\subsubsection{PCR amplification}

The extracted DNA was amplified using PCR technique in the Eppendorf gradient thermal cycler with the aim of studying genetic variability of in vitro callus of O.basilicum. The genomic DNA was amplified using four primers. Each primer is a 10mer of arbitrary sequence: 1(5'-TGCCGAGCTG-3'), 2(5'-TCGTTCCGCA-3'), 3(5'-CACCTTTCCC-3'), and 4(5'-GTGCAACGTG-3') (GE healthcare, UK). PCR amplification was performed in $20 \mu \mathrm{L}$ reaction mix containing $40 \mathrm{ng}$ genomic DNA for 45 cycles. The following conditions were followed: i) $92^{\circ} \mathrm{C}$ initial denaturation for $5 \mathrm{~min}$, ii) $92^{\circ} \mathrm{C}$ denaturation step for $30 \mathrm{~s}$,iii) $33^{\circ} \mathrm{C}, 33.6^{\circ} \mathrm{C}, 32.5^{\circ} \mathrm{C}$ and $32^{\circ} \mathrm{C}$ annealing for $1 \mathrm{~min}$ for each primer respectively and iv) $72^{\circ} \mathrm{C}$ extension for $2 \mathrm{~min}$ followed by a final extension of $72^{\circ} \mathrm{C}$ for $5 \mathrm{~min}$. Reactions were carried out in a volume of $20 \mu \mathrm{L}$ containing $10 \mu \mathrm{L}$ of PCR master mix (2x) (Merck Specialties, Mumbai) solution with $4 \mu \mathrm{L}$ of nuclease free water, $3 \mu \mathrm{L}$ of primer and $3 \mu \mathrm{l}$ of template DNA. The final product was separated and visualized using agarose gel electrophoresis.

\subsubsection{Electrophoresis of genomic DNA}

The PCR product was separated by horizontal electrophoresis through 1.5\% agarose gel 
mixed with ethidium bromide $(0.5 \mathrm{mg} / \mathrm{mL})$ for 45 $\mathrm{min}$ at $50 \mathrm{~V}$ in tris acetate EDTA buffer ( $40 \mathrm{mM}$ Tris; 2 mM EDTA; $20 \mathrm{mM}$ Glacial acetic acid pH8) (Sambrooket al., 2001). The samples were mixed well with loading dye (1:1) and the samples were gently loaded on to the wells using a disposable micropipette tip. The bands were visualized using gel documentation system (Biorad, Italy).

\section{RESULTS AND DISCUSSION}

\subsection{Callus induction}

Leaf explant of Ocimum basilicum was cultured on half strength MS medium supplemented with IAA at different concentrations. Medium devoid of hormone did not show any response on callus induction. The inoculated leaf explants of $O$. basilicum on medium containing IAA induced callus after a week of culture. Out of ten different concentrations tested, $0.28 \mu \mathrm{M}$ failed to induce callus. Good callus proliferation was observed on medium containing $0.56 \mu \mathrm{M}$ to $1.40 \mu \mathrm{M}$ IAA. Formation of anthocyanin like pigments from callus was recorded at concentration $0.84 \mu \mathrm{M}$ and $1.12 \mu \mathrm{M}$ IAA (Fig. 1). Root induction was observed with increase in concentration (Fig. 2). In vitro culture of medicinal plants (Shohael et al.,2006; Shin et al.,2008; Jeong et al.,2009; Park et al.,2012) with the objective to isolate secondary metabolites or altering or enhancing the concentration of secondary metabolites (Schijlen et al.,2006, Dorais et al.,2008) has been well established.Owing to callus itself had the ability to produce secondary metabolites, plant tissue culturists use this capacity to gain many useful chemicals via callus culture in vitro such as flavor and fragrance, pigment and pharmaceutical compounds (Ram et al., 2011).

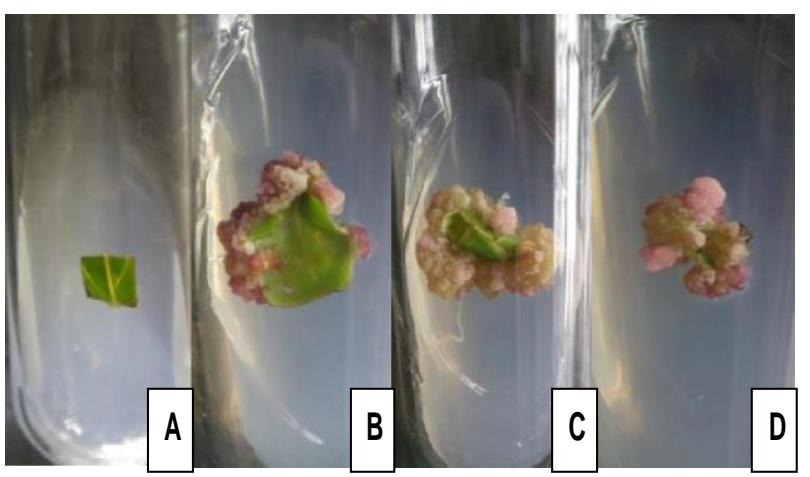

Fig. 1. Formation of Anthocyanin like pigments on Callus.

In the present study, $O$. basilicum callus induced on the MS medium containing lower concentrations of IAA released anthocyanins. This result indicated that plant growth regulator is necessary for the production of valuable secondary metabolites.

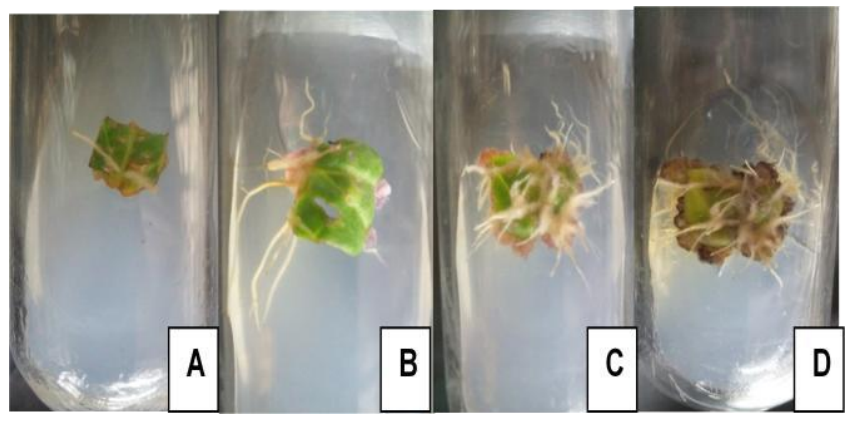

Fig. 2. Root induction from Leaf explants

\subsection{RAPD analysis}

The genetic level variation of in vitro developed callus was accessed through RAPD analysis (Fig 3). The result of RAPD analysis indicates in vitro developed callus was slightly polymorphic. The polymorphic banding pattern possibly indicates that there was a genetic level variation.

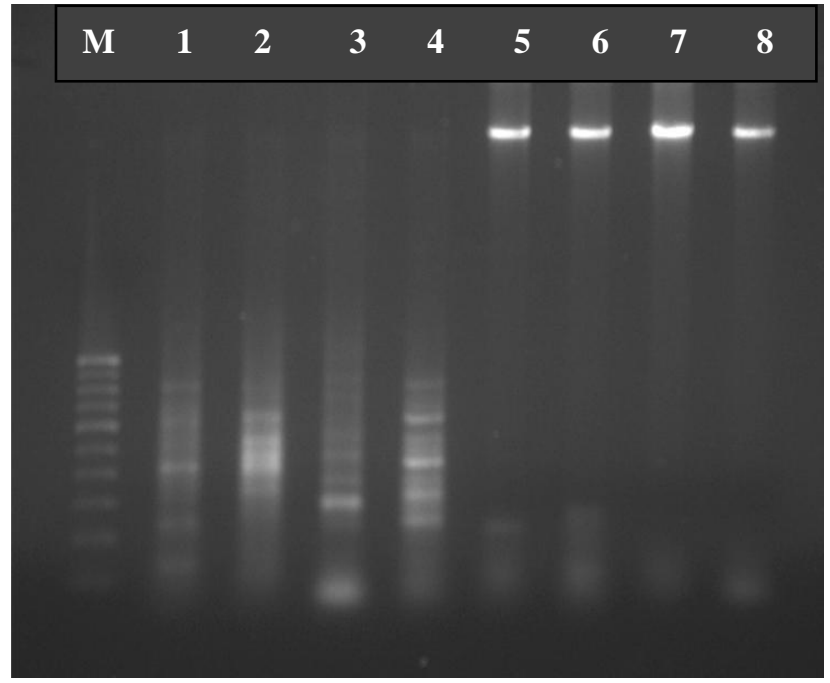

Fig. 3: RAPD analysis of in vitro callus.

Random amplified polymorphic DNA (RAPD) markers have proved to be very useful tool providing a convenient and rapid assessment of the genetic differences between genotypes (Williams et al., 1990). Moreover, RAPD use arbitrary primers that provide a large number of multilocus markers and can be applied to analyze almost any organism even those for which no previous genetic or molecular information are available. RAPD is referred as an appropriate tool for certification of genetic fidelity of in vitro propagated plants (Gupta 
and Rao, 2002). The polymorphic banding pattern in the callus of $O$. basilicumpossibly indicates that there is a negligible level of genetic variation. Bernhardt et al. (2014) have evaluated the RAPD banding pattern of eight different 0 . basilicum gene bank accessions and have reported similar result. Anamika et al. (2010) reported the same condition in Pogostemoncablin. Rady and Nazif (2005) reported that in vitro shoots of 0 . americanum gave polymorphic bands by using the random primers.

The current outcome for 0 . basilicum pointed out that IAA exactly had the influence on the antioxidant property of the callus. Similar results for antioxidant activity of $O$. basilicumhave been reported in the literature (Javanmardi et al., 2003; Seung-Joo Lee et al., 2004; Politeo et al., 2007; Gulcin et al., 2007).

\section{REFERENCES}

Anamika P., Ganesh Thapa, Adreeja Basu, PurabiMazumdar, Mohan Chandra Kalita and LingarajSahoo, (2010). Rapid plant regeneration, analysis of genetic fidelity and essential aromatic oil content of micropropagated plants of Patchouli, Pogostemoncablin (Blanco) Benth. - An industrially important aromatic plant, Indus. Crop Prod. 32: 366-374.

Bernhardt, B., FazekasGy, M. Ladanyi, K. Inotai, E. Zambori-Nemeth, J. Bernath and K. Szabo, (2014). Morphological-, chemical- and RAPDPCR evaluation of eight different Ocimum basilicum L. gene bank accessions. J. Appl. Res. Med. Arom. Plant, 1: 23-29.

Chopra, R.N., S.L. Nayar and I.C. Chopra, (1986). Glossary of Indian Medicinal Plants.Council of Scientific and Industrial Research, New Delhi, p. 256.

Dorais, M., D.L. Ehret and A.P. Papadopoulos, (2008). Tomato (Solanumlycopersicum) health components, from the seed to the consumer. Phytochem. Rev. 7: 231-250.

Gulcin, I., Mahfuz Elmastat and Hassan Y. Aboul Enein, (2007). Determination of Antioxidant and Radical Scavenging Activity of Basil (OcimumbasilicumL.) assayed by Different Methodologies. Phytother. Res., 21: 354-361.

Gupta, P.K. and J.K. Rao, (2002). Molecular markers in crop improvement present status and future needs in India. Plant Cell Tissue Org. Cult. 70: 229-234.
Javanmardi, J., C. Stushnoff, E. Locke and J.M. Vivanco, (2003). Antioxidant activity and total phenolic content of Iranian Ocimum accessions. Food Chem., 83: 547-550.

Jayasinghe, C., N. Gotoh, T. Aoki and S. Wada, (2003). Phenolics composition and antioxidant activity of sweet basil (OcimumbasilicumL.). J. Agric.. Food Chem. 51: 4442-4449.

Jeong, J.H., Y.S. Kim, H.K. Moon, S.J. Hwang and Y.E. Choi, (2009). Effects of LED on growth, morphogenesis and eleutheroside contents of invitro cultured plantlets of Eleutherococcus senticosus Maxim. Korean J. Med. Crop Sci., 17: 39-45.

Nyak, V. and D.P. Uma, (2005). Protection of mouse bone marrow against radiation-induced chromosome damage and stem cell death by Ocimum flavonoids Orientin and vicenin. Radiation Res., 163: 165-171.

Padmalatha, K., and M.N.V. Prasad, (2006). Optimization of DNA isolation and PCR protocol for RAPD analysis of selected medicinal and aromatic plants of conservation concern from Peninsular India. African J. Biotechnol., 5: 230234.

Park, S.U., D.J. Ahn, H.J. Jeon, T.R. Kwon, H.S. Lim, C.B.S. Baek and K.H. BaeHanhong, (2012). Increase in the contents of Ginsenosides in raw ginseng roots in response to 450 and $470 \mathrm{~nm}$ light from Light-Emitting Diodes. J. Ginseng Res., 36: 198-204.

Politeo, O., M. Jukic and M. Milos, (2007). Chemical composition and antioxidant capacity of free volatile aglycones from basil (Ocimum basilicum L.) compared with its essential oil. Food Chem., 101: 379-385.

Rady, M.R. and N.M. Nazif, (2005). Rosmarinic acid cotent and RAPD analysis of in vitro regenerated basil (Ocimum americanum) plants. Fitoterapia,76: 525-533.

Ram, M., K.V. Prasad, C. Kaur, S.K. Singh, A. Arora and S. Kumar, (2011). Induction ofanthocyanin pigments in callus cultures of Rosa hybrida L. in response to sucroseand ammonical nitrogen levels. Plant Cell Tissue Org. Cult., 104: 171-179.

Schijlen, E., C.H. RicdeVos, H. Jonker, H.V.D. Broeck, J. Molthoff, A.V. VanTunen, S. Martens and A. Bovy, (2006). Pathway engineering for healthy phytochemicals leading to the production of 
novel flavonoids in tomato fruit. Plant Biotechnol. J. 4(4): 433-444.

Seung-Joo Lee, Katumi Umano, Takayuki Shibamoto and Kwang-Geun Lee, (2005). Identification of volatile components in basil (Ocimum basilicum L.) and thyme leaves (Thymus vulgaris L.) and theirantioxidant properties. Food Chem., 91: 131-137.

Shohael, A.M., M.B. Ali, K.W. Yu, E.J. Hahn, R. Islam and K.Y. Paek, (2006). Effect of light on oxidative stress, secondary metabolites and induction of antioxidant enzymes in
Eleutherococcus senticosus somatic embryos in bioreactor. Process Biochem., 41: 1179-1185.

Williams, J.G.K., A.R. Kubelik, K.J. Livak, J.A. Rafalski and S.V. Tingey, (1990). DNA polymorphism amplified by arbitrary primers are useful as genetic markers. Nucleic Acids Res., 18: 65316535.

Zheljazkov, V.D., A.N. Callahan and C.L. Cantrell, (2007). Yield and Oil Composition of ThirtyEight Basil (Ocimum basilicumL.)Accessions Grown in Mississippi. J. Agricult. Food Chem., 56: 241-245. 